\title{
Hemidiaphragmatic paresis after cervical herpes zoster
}

\author{
L DERVEAUX, LM LACQUET
}

From the Department of Pathophysiology, Academisch Ziekenhuis, Pellenberg, Belgium

Herpes zoster generally affects sensory nerves, but occasionally motor nerves also are affected, ${ }^{12}$ so that flaccid muscle paresis develops in the segments corresponding to the dermatomes in which cutaneous lesions appear. The site of the lesion in the motor neurone is not clear, but the absence of electromyographic fasciculations and slow motor conduction velocity point to motor axon damage. Postherpetic paresis of the diaphragm has been reported in rare instances. ${ }^{34}$ In the present case it developed on the left side after ipsilateral cervical herpes zoster, with the electromyographic signs of neurogenic paresis of other muscles in the same segments.

\section{Case report}

A 74-year-old man had attended our outpatient clinic since 1977 at six-month intervals for chronic bronchitis and emphysema. In March 1980 pulmonary function was clearly diminished (table), and the chest radiograph showed hyperinflation and creased peripheral vascular markings (fig, a).

In July 1980 he experienced severe pain followed by an extensive vesicular skin eruption in the left cervical region, which the family doctor diagnosed as herpes zoster. In Sep-

Address for reprint requests: Dr LM Lacquet, Academisch Ziekenhuis, 3041 Pellenberg, Belgium.

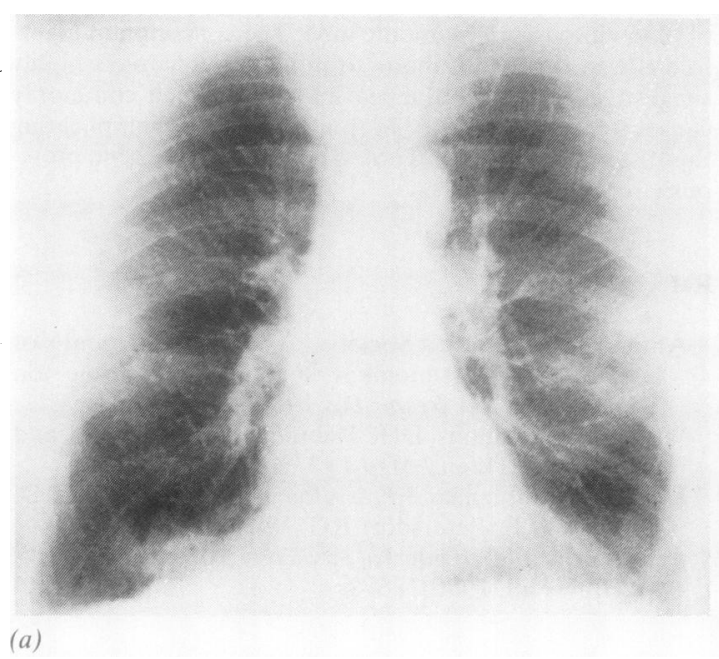

'tember 1980 the patient said that his shortness of breath had increased slightly since he had had the eruption. The leftsided neck pain had subsided except for some itching and numbness. Breath sounds were absent over the left lung base. The left cervical skin showed the characteristic segmental distribution of pigmented herpetic scars; sensory and motor nerve supply appeared to be intact on both sides of the neck and shoulders. On the posteroanterior chest radiograph taken in full inspiration the left hemidiaphragm was positioned $8.1 \mathrm{~cm}$ higher than the right (fig, $b$ ). Fluoroscopy showed retarded, slow, limited downward movement of the raised dome during deep inspiration and paradoxical movement on sudden inspiration and on sniffing. Phrenic motion was recorded on video tape for later comparison. The posteroanterior and oblique tomograms of $\vec{\varphi}$ the upper mediastinum and hilar regions, the oesophagogram, and plain films of the abdomen (in the supine and erect positions) were normal. Radiographs of the cervical spine showed moderate bilateral arthrosis. The results of pulmonary function tests had not changed appreciably (table). On fibreoptic bronchoscopy we found only moderate mucosal oedema and hyperaemia, compatible with chronic bronchitis. Routine blood tests gave normal results, and cytological and bacteriological examinations of sputum and bronchial washings were negative. The electromyogram of the second to fifth cervical myotomes (C2-5) was normal on the right side. On the left side at rest the trapezius,

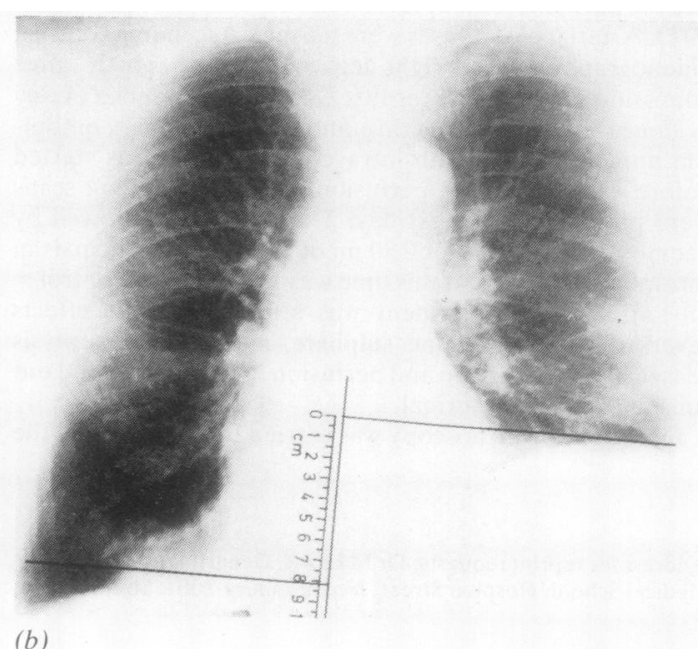

(b)

Hemidiaphragmatic paresis after cervical herpes zoster in a man with chronic bronchitis and emphysema: (a) first low position of the diaphragm due to emphysema, followed by (b) left-sided paresis (September 1980). Two straight lines, tangential to the highest point of either dome and perpendicular to the axis of the spine, determine the difference in level. ${ }^{5}$ 
Sequential measurements of pulmonary function (percentage of predicted value in parentheses)

\begin{tabular}{|c|c|c|c|c|}
\hline Date & $\begin{array}{l}V C \\
(l)\end{array}$ & $\begin{array}{l}F E V_{1} \\
(l)\end{array}$ & $F E V_{1} / V C$ & $\begin{array}{ll}C \quad & T L C O \\
& \left(\operatorname{ml~min}^{-1}\right. \\
& \left.\mathrm{mm} \mathrm{Hg}^{-1}\right)\end{array}$ \\
\hline $\begin{array}{l}\text { Mar } 1980 \\
\text { July } 1980 \\
\text { Sept } 1980 \\
\text { Nov } 1980 \\
\text { Feb } 1981\end{array}$ & $\begin{array}{l}3.03(70) \\
3 \cdot 13 \quad(73) \\
3 \cdot 20 \quad(75) \\
3.25 \quad(77)\end{array}$ & $\begin{array}{l}1.02(37) \\
\text { herpetic er } \\
1.12(41) \\
0.80(29) \\
1.20(44)\end{array}$ & $\begin{array}{l}0.34 \\
\text { ruption } \\
0.36 \\
0.25 \\
0.37\end{array}$ & $\begin{array}{l}14 \cdot 8(60) \\
\overline{14} \cdot 6(58)\end{array}$ \\
\hline
\end{tabular}

VC - vital capacity; TLCo - transfer factor.

deltoid and rhomboid muscles showed denervation fibrillations and positive sharp waves in salvo; on contraction the tracing derived from the sternocleidomastoid was slightly impoverished and accelerated. The diaphragmatic response to stimulation of the phrenic nerve at Erb's point, recorded through an oesophageal electrode, showed a normal latency time of $9 \mathrm{~ms}$ on the right and no muscle action potentials on the left side.

In November 1980 and February 1981 the difference between left and right diaphragmatic domes at full inspiration had decreased to 5 and $3.3 \mathrm{~cm}$ respectively. The paradoxical movement of the left hemidiaphragm on deep inspiration and sniffing had disappeared. The electromyogram of the left-sided cervical muscle groups had returned to normal patterns; a control electromyogram of the diaphragm was refused.

\section{Discussion}

The phrenic nerve originates mainly in C4 and partly in C3 and C5, segments that also supply the affected shoulder muscles; the sternocleidomastoid and trapezius are innervated by the accessory nerve, which has a cranial as well as a cervical spinal root and also receives branches from the cervical plexus. We postulate a causal relation between the observed phrenic paresis and the herpes zoster affection for the following reasons: firstly, the phrenic motor nerve block coincided with electromyographic features typical of neurogenic paresis in ipsilateral neck and shoulder muscles; secondly, the phrenic paresis came to our attention only two months after the herpetic eruption and did not exist four months before it, and it subsequently regressed when the neck paresthesiae improved and the electromyogram of neck and shoulder returned to normal; and, thirdly we ruled out other known causes of phrenic lesions - for example, mediastinal inflammatory and neoplastic disease, pneumonia, pleural effusion, trauma, subphrenic abscess and other abdominal infections. ${ }^{\circ}$
As usually happens in the unilateral condition, ${ }^{7}$ our patient tolerated the diaphragmatic paralysis remarkably well despite his severe chronic obstructive lung disease. The transdiaphragmatic pressure at maximum inspiration, another valuable index of phrenic function, ${ }^{8}$ was $21 \mathrm{~cm} \mathrm{H} \mathrm{H}_{2} \mathrm{O}$ in November 1980 and $17 \mathrm{~cm} \mathrm{H}_{2} \mathrm{O}$ in February 1981 (normal value $>25 \mathrm{~cm} \mathrm{H}_{2} \mathrm{O}$ ). These low pressures should not, however, be taken as evidence of diaphragmatic paresis since the emphysema of our patient could have produced the same defect. ${ }^{9}$

The case suggests that in some instances so-called idiopathic paralysis of the diaphragm could be related to herpes zoster. It must still be differentiated from malignant invasion of the mediastinum; this problem is compounded by the fact that malignant disease itself can predispose to herpes zoster.

We acknowledge the help of Dr J De Meirsman with the electromyography.

\section{References}

' Taterka JK, O'Sullivan ME. Motor complications of herpes zoster. JAMA 1943;122:737-41.

${ }^{2}$ Pathy MS. Motor complications of herpes zoster. Age Ageing 1979;8:75-80.

${ }^{3}$ Parker GW, Ramos ED. Paralysis of the phrenic nerve following herpes zoster. JAMA 1962;180:148-50.

${ }^{4}$ Brostoff J. Diaphragmatic paralysis after herpes zoster. Br Med J 1966;ii:1571-2.

5 Wynn-Williams N. Hemidiaphragmatic paralysis and paresis of unknown aetiology without any marked rise in level. Thorax 1954;9:299-303.

${ }^{6}$ Riley EA. Idiopathic diaphragmatic paralysis: a report of eight cases. Am J Med 1962;32:404-16.

${ }^{7}$ Douglass BE, Clagett OT. The prognosis in idiopathic diaphragmatic paralysis. Dis Chest 1960;37:294-7.

${ }^{8}$ Newson-Davis J. The diaphragm and neuromuscular disease. Am Rev Respir Dis 1979;119:115-7.

9 Druz WJ, Danon J, Fishman HC, Goldberg NB, Moisan TC, Sharp TJ. Approaches to assessing respiratory muscle function in respiratory disease. Am Rev Respir Dis 1979;119:145-9.

${ }^{10}$ Mazur MH, Dolin R. Herpes zoster at the NIH: a 20-year experience. Am J Med 1978;65:738-44. 